\title{
Thermo-chemical Fluid Flow Simulation in Hot-Dip Galvanizing: The Evaluation of Dross Build-Up Formation
}

\author{
GEORG REISS, ANTON ISHMURZIN, CLAUDIA MUGRAUER, WERNER EßL, \\ WERNER ECKER, JOHANN STRUTZENBERGER, HARALD UNGER, \\ and GERHARD ANGELI
}

\begin{abstract}
This paper presents a new computational framework to investigate the driving force for the formation of intermetallic dross particles in the zinc bath and dross build-up on the bath hardware. This is a major problem in continuous hot-dip galvanizing lines. The Computational Fluid Dynamics (CFD) model calculates the turbulent thermo-chemical flow conditions within the liquid melt. A detailed modeling of the steel strip-liquid interface enhances this approach, by means of a conjugated heat transfer calculation and a spatially resolved, temperature- and concentration-dependent iron dissolution and aluminum uptake. The heart of the computational framework is a thermodynamic model, which assesses the driving force for the formation or dissolution of dross particles in the bath and dross build-up on stationary and rotating equipment. The simulation results are validated with temperature and species depth profile measurements. The applicability of the CFD model is shown by investigating the locally resolved aluminum uptake and iron dissolution at the steel-strip surface, and the multi-physics conditions in the region near the roll. The novel approach of evaluating the thermodynamic driving force enables the assessment of the formation of dross build-up at the roll surface.
\end{abstract}

https://doi.org/10.1007/s11663-018-1496-0

(C) The Author(s) 2019

\section{INTRODUCTION}

HoT-DIP galvanizing process is the main metallurgical process for continuous zinc coating of a steel strip, wherein the steel is immersed into a molten zinc alloy operated at temperatures in the range of $450{ }^{\circ} \mathrm{C}$ to $480{ }^{\circ} \mathrm{C}$. In fact, 90 pct of the coated steel sheets in the United States are produced by hot-dip galvanizing. ${ }^{[1]}$ The increasing demand for smooth and thin surface coatings from the processing industry, as well as various cost saving targets in the process chain, have pushed plant operation to its limits, so that practical expertise no longer suffices. This has led to the development of physically based simulation models in order to better understand and assess the hot-dip galvanizing process.

GEORG REISS, ANTON ISHMURZIN, CLAUDIA MUGRAUER, WERNER EßL, and WERNER ECKER are with the Materials Center Leoben Forschung GmbH, Roseggerstraße 12, 8700, Leoben, Austria. Contact e-mail: georg.reiss@mcl.at JOHANN STRUTZENBERGER, HARALD UNGER, and GERHARD ANGELI are with the voestalpine Stahl GmbH, voestalpine-Straße 3, 4020, Linz, Austria.

Manuscript submitted May 7, 2018.

Article published online January 9, 2019.
The coating process consists of several individual steps, starting from the pre-treatment of the steel sheet in furnaces, over the dipping in the zinc bath, to the wiping of the liquid coating utilizing air knives after exiting the bath, and solidification of the coating in cooling towers. ${ }^{[2]}$ This paper focuses on the zinc bath, but other research for furnaces ${ }^{[3,4]}$ gas jet wiping ${ }^{[5,6]}$ and solidification modeling ${ }^{[7]}$ has been done as well.

The pre-treated steel strip enters the liquid zinc bath from the furnace, with a temperature close to the bath temperature. It is guided through the bath by stabilization rolls. The thickness of the liquid zinc film is adjusted with gas jet wiping knives. A view of the zinc bath geometry can be seen in Figure 1.

In order to obtain a good adherence of the liquid zinc on the steel surface, the bath contains aluminum, whose concentration varies from 0.11 to $0.13 \mathrm{wt}$ pct for galvannealed (GA) products and is typically set around $0.2 \mathrm{wt}$ pet for galvanized (GI) products. The consumed zinc and aluminum are supplied to the bath by zinc alloy ingots usually containing 0.5 wt pet of aluminum. Inductive heating compensates for the heat loss across the walls and the surface, as well as the energy required for melting the ingots. Iron dissolves from the steel strip into the zinc aluminum melt forming a ternary $\mathrm{Zn}-\mathrm{Al}-\mathrm{Fe}$ system, which is likely to produce a solid Fe-Al based 


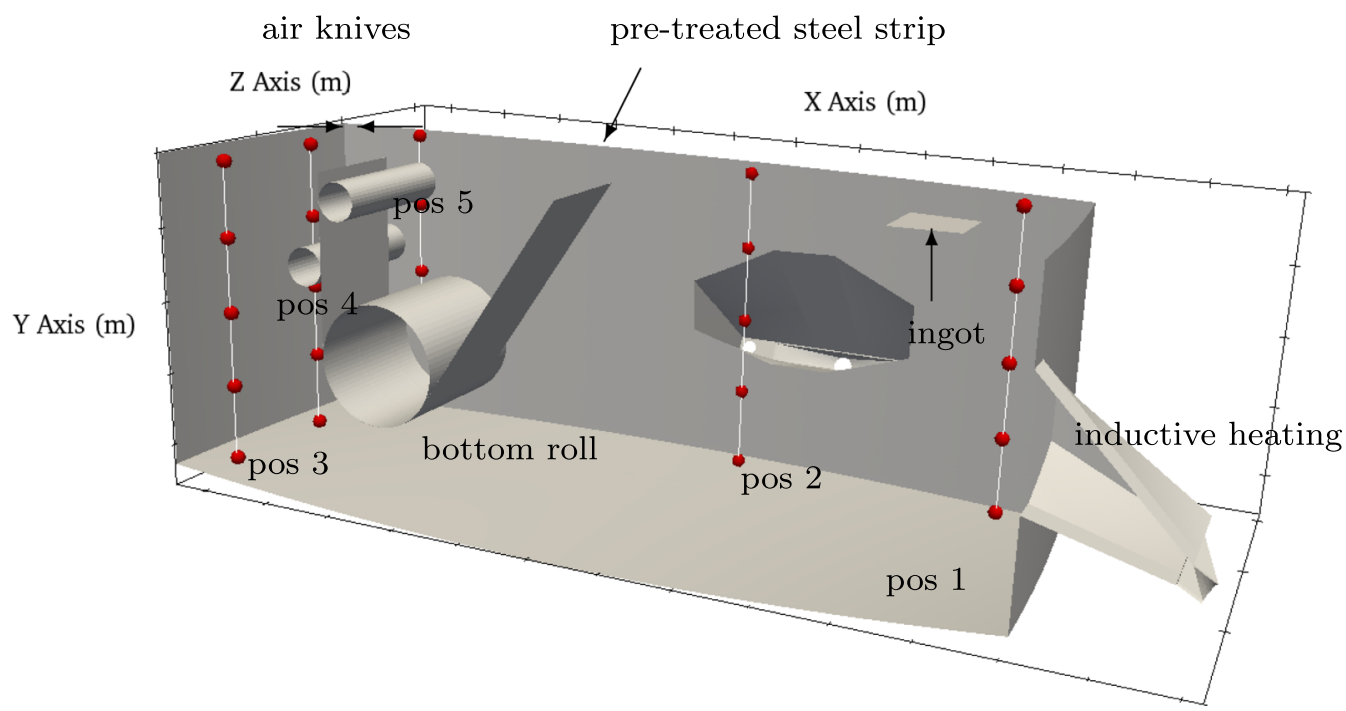

Fig. 1-Depiction of computational geometry of operating zinc bath. The steel strip emerges from the furnace and is conducted by stabilization rolls through the zinc bath. After it leaves the zinc bath, the coating thickness is adjusted with gas jet wiping. The bath temperature level is maintained by inductive heating and the bath level is held constant by charging of ingots. In addition, the locations of the measurement positions (1 to 5) and the thermocouples (red dots) for the temperature distribution are depicted (Color figure online).

phase $\left(\eta \mathrm{Fe}_{2} \mathrm{Al}_{5} \mathrm{Zn} n_{x}\right)$ and solid Zn-Fe-based phases $\left(\zeta \mathrm{FeZn}_{13} \mathrm{Al}_{x}\right.$ and $\left.\delta \mathrm{FeZn} n_{7}\right)$, depending on the local temperature and concentration distribution. ${ }^{[8,9]}$ These solid phases precipitate as dross particles in the bath or as dross build-up on the immersed bath hardware and decrease the quality of the zinc coating.

State-of-the-art studies have tried with varying complexity (and focus) to simulate the concentration and temperature distribution in the bath and near the steel strip: Model-based 1D approaches have been applied to assess the temperature distribution in the steel strip, the iron dissolution at the solid-liquid interface, as well as the aluminum uptake in the coating layer. ${ }^{[10-13]}$ It was shown that the local temperature and also concentration gradients significantly influence the dissolution of iron and the uptake of aluminum. These approaches are fast and robust, but lack a detailed resolution of the temperature and species distribution within the entire zinc bath.

More sophisticated 3D models offer a better insight into the underlying processes. Different numerical studies have investigated the temperature and species distribution within the zinc bath using complex CFD models, ${ }^{[14]}$ where the solubility of iron and aluminum is computed by a thermodynamic function. An extension of this work, including the computation of the iron distribution and more elaborated thermodynamics, has been carried out. ${ }^{[15,16]}$ The supply of aluminum during the ingot melting was modeled, and the consumption of aluminum on the strip surface was presumed to be constant, while no iron dissolves from the steel strip. It was shown in conjugated heat transfer simulations that the steel strip soon adapts to the bath temperature, and generates local temperature distributions. ${ }^{[17]}$ The effect of different strip immersing temperatures and their global effect on the iron dissolution and aluminum uptake rates is reported in Reference 18.
The current study combines many of the above-mentioned qualities, to yield a more realistic CFD model of the flow, temperature, and species distribution within the molten zinc bath. The accurate computation of these distributions is the basic requirement for the novel investigation of the driving force for dross build-up on the bath hardware. A thermal turbulent flow with a Boussinesq approximation is set up, including the conjugated heat transfer coupling between the liquid zinc bath, the solid steel strip, and the bath rolls. The thermal boundary conditions of the walls and the surface are obtained by measurement and are already validated ${ }^{[19]}$ Distribution of aluminum and iron, as well as the dross concentration, is calculated by solving transport equations, with source terms for the melting of the ingot, as well as a spatially resolved temperatureand concentration-dependent aluminum uptake and iron dissolution at the steel-strip surface. Finally, the thermodynamic model determines the state of the molten zinc alloy in the entire zinc bath and in the vicinity of the bath hardware and if formation of dross build-up is likely to occur. This enables the different operating conditions and their effect on the dross build-up to be evaluated.

\section{MATHEMATICAL MODELING}

A detailed mathematical description of the physical processes in the zinc bath comprises the solution of the flow equations in conjunction with turbulence modeling. In addition, the buoyant effects have to be taken into account, requiring the computation of the temperature field in the zinc bath, including the coupled heat transfer from the steel strip, the heat losses over the zinc surface, the bath walls, and the ingot melting. Moreover, the species distribution of aluminum and iron, as well as the 
solid dross phases are determined by solving the transport equations, taking source terms and thermodynamics into account.

\section{A. Fluid Flow and Turbulence}

One standard procedure to compute the fluid flow is to solve the Navier-Stokes equations together with the continuity equation. This can be done by employing the finite volume method, which discretizes the partial differential equations by integrating them over a control volume, ensuring conservation. ${ }^{[20]}$ The continuity equation accounts for the mass conservation in the system:

$$
\frac{\partial \rho}{\partial t}+\nabla \cdot(\rho \boldsymbol{u})=\boldsymbol{0}
$$

In order to account for turbulence, the flow equations are time-averaged yielding the Reynolds-averaged Navier-Stokes (RANS) equations:

$$
\frac{\partial \rho \boldsymbol{u}}{\partial t}+\boldsymbol{u} \cdot \nabla \rho \boldsymbol{u}=-\nabla p+\nabla \cdot\left(\mu \nabla \boldsymbol{u}-\tau_{i j}^{\prime}\right)-\rho \boldsymbol{g} \beta_{T}\left(T-T_{0}\right)
$$

In this procedure, the velocity is decomposed into a sum of a mean velocity $\boldsymbol{u}$ and a fluctuation of the velocity $\boldsymbol{u}^{\prime}$. Once the equations are averaged and all the math is done, an additional term $\tau_{i j}^{\prime}$ remains in the momentum equation which is denoted as Reynolds stress tensor, which has to be modeled. ${ }^{[21]}$ The last term in Eq. [2] accounts for density variations caused by temperature $T$. It represents a Boussinesq approach, where the local changes of the density $\rho$ are modeled with a thermal expansion coefficient $\beta_{T}\left(\mathrm{~K}^{-1}\right)$ and the gravity vector $\boldsymbol{g}$. This approach showed good results for previous studies on zinc bath flows. ${ }^{[15]}$

Various turbulence models describe the Reynolds stress tensor. The most widely used and stable approach is the $k-\epsilon$ model, which models the stress tensor as an additional turbulent viscosity, assuming that the underlying principle of the Reynolds stresses is based on similar phenomena as the viscous stresses. ${ }^{[22]}$ However, the turbulent viscosity can be orders of magnitude higher than the molecular viscosity and is determined by solving two additional transport equations for the kinetic turbulent energy $k$ and the turbulent dissipation $\epsilon$. For further information, the reader is referred to standard literature on turbulence modeling. ${ }^{[20,21,23]}$ In this study, the RNG $k-\epsilon$ model has been employed. Unlike the standard $k-\epsilon$ model, it uses a differential formula for the effective viscosity in low-Reynolds number regions, which are large in the zinc bath. ${ }^{[22]}$ As a result, the effective thermal conductivity and species diffusivity can be more accurately computed by the RNG $k-\epsilon$ model, especially in stagnant regions, where the mixing by turbulence would be highly overestimated by standard $k-\epsilon$ models.
Since it is not feasible to resolve the very thin boundary layer of the flow, wall functions are used to calculate the velocity in the first cell layer, based on the shear stress at the wall. A detailed derivation and description of its applicability and limits can be found in References 21 and 22. The turbulence-dependent shear stress takes into account the movement of the steel strip and the rolls, since their velocity is prescribed to the fluid-solid interface. A scalable wall function approach is applied in this study. This approach uses the standard wall functions, whenever the $y^{+}$values are appropriate, and limits the deterioration for lower $y^{+}$-values. ${ }^{[24]}$

\section{B. Thermal Modeling}

The temperature distribution within the zinc bath can be computed by solving the energy equation:

$$
c_{p} \frac{\partial \rho T}{\partial t}+\boldsymbol{u} \cdot \nabla \rho T=\nabla \cdot\left(\left(\lambda+\lambda_{t}\right) \nabla T\right)+q_{T},
$$

where $c_{p} \quad\left(\mathrm{~J} \mathrm{~kg}^{-1} \mathrm{~K}^{-1}\right)$ is the specific heat, $\lambda\left(\mathrm{J} \mathrm{s}^{-1} \mathrm{~m}^{-1} \mathrm{~K}^{-1}\right)$ the thermal conductivity, and $\lambda_{t}$ an additional conductivity depending on the turbulent properties of the flow. The source term $q_{T}\left(\mathrm{~J} \mathrm{~m}^{-3} \mathrm{~s}^{-1}\right)$ accounts for the heat loss during the ingot melting.

In addition to the temperature field in the fluid region, the heat transport in the solid steel strip is calculated by solving the heat transport equation ${ }^{[17]}$ :

$$
\rho_{s} c_{p_{s}}\left(\frac{\partial T_{s}}{\partial t}+\boldsymbol{u}_{s} \cdot \nabla T_{s}\right)=\nabla \cdot\left(\lambda_{s} \nabla T_{s}\right)
$$

The density $\rho_{s}$, specific heat $c_{p_{s}}$, and the thermal conductivity $\lambda_{s}$ refer to the material parameters of the solid. The additional term $\rho_{s} c_{p_{s}} \boldsymbol{u} \cdot \nabla T_{s}$ offers the opportunity to include the movement of the solid in the modeling of the solid temperature $T_{s}$, as needed for the moving steel strip. Newton's cooling law terms are introduced in order to facilitate the heat transfer between solid and fluid regions ${ }^{[25]}$ :

$$
Q_{T_{s}}=-Q_{T_{f}}=h_{e f f}\left(T_{f}-T_{s_{w}}\right) .
$$

The wall heat fluxes $Q_{T_{i}}\left(\mathrm{~J} \mathrm{~s}^{-1} \mathrm{~m}^{-2}\right)$ can be determined by means of the convective heat transfer coefficient $h_{\text {eff }}\left(\mathrm{J} \mathrm{s}^{-1} \mathrm{~m}^{-2} \mathrm{~K}^{-1}\right)$, which is calculated from the local turbulence field. ${ }^{[1]}$ Further, $T_{f}$ is the liquid temperature in the first cell adjacent to the solid wall interface with temperature $T_{S_{w}}$.

The thermal boundary conditions for the walls, as well as the surface (free and covered with dross), are convective boundary conditions, derived from thermal measurements. The temperature of the walls and of the liquid zinc of a cooling bath was measured. The corresponding heat transfer coefficients at the boundaries were adapted to reproduce the transient cooling measurements in the simulation. The implementation and validation can be found in Reference 19 . 


\section{Species Transport}

The concentration distribution in the zinc alloy is determined by the solution of a dilute Fick-diffusion model:

$$
\begin{aligned}
\frac{\partial \rho y_{i}}{\partial t}+\boldsymbol{u} \cdot \nabla \rho y_{i}= & \nabla \cdot\left(\rho\left(D_{i j}+D_{t}\right) \nabla y_{i}\right)+q_{R_{i}}+q_{I_{i}} \\
& +q_{S_{i}}+q_{O_{i}},
\end{aligned}
$$

where $y_{i}$ is the mass fraction of species $i$ (e.g., Al, Fe, $\left.\mathrm{Fe}_{2} \mathrm{Al}_{5}, \mathrm{FeZn}_{7}\right), D_{i j}\left(\mathrm{~m}^{2} \mathrm{~s}^{-1}\right)$ is the binary diffusion coefficient, and $D_{t}$ is the turbulent diffusivity. The terms $q_{R_{i}}, q_{I_{i}}, q_{S_{i}}$, and $q_{O_{i}}\left(\mathrm{~kg} \mathrm{~m}^{-3} \mathrm{~s}^{-1}\right)$ are species source terms due to chemical reactions, ingot melting, reactions at the strip surface, and the species leaving the bath due to drag caused by the moving steel strip. The modeling of these source terms is discussed in more detail in Section II-D.

Equation [6] is solved for $N-1$ species, while the mass fraction of the $N$ th-species (zinc) is calculated as

$$
y_{Z n}=1-\sum_{i=1}^{N-1} y_{i}
$$

In this approach, the solid $\delta$ - and $\eta$-phases are treated as additional species in the zinc bath. This reduces the required simulation effort, as no additional solid particle models have to be employed. Their transport is calculated by Eq. [6]. This approach allows accounting for the reaction kinetics of formation and dissolution of these solid phases.

\section{Definition of Source Terms}

The following sections cover the various source terms and their implementation.

\section{Chemical reaction}

State-of-the-art modeling approaches assume that the occurring chemical reaction rates are infinitely high, resulting in a instantaneous precipitation if the solution exceeds the thermodynamic solubility limit. ${ }^{[15,18]}$ In reality, the precipitation of dross particles will take some time. The investigation of these phenomena needs to be further studied. The current thermodynamic state in each computational cell is evaluated according to the thermodynamic data presented in Section II-E. If the solubility limit is exceeded, the source term is set:

$$
q_{R_{i}}=f_{R} \rho\left(y_{i_{e q}}-y_{i}\right),
$$

where $y_{i_{c}}$ is the equilibrium mass fraction of species $i$, and $f_{R}\left(\mathrm{~s}^{-1}\right)$ is an arbitrary time constant in the range of $0 \leq f_{R} \leq 1 / \Delta t$. Setting $f_{R}$ to the reciprocal time step $\Delta t$ corresponds to an infinitely high reaction rate, while setting $f_{R}=0$ suppresses all reactions.

\section{Ingot melting}

During the production process, a constant melt level in the zinc bath is tried to be achieved by continuous melting of zinc ingots to account for the melt that is withdrawn by the steel strip. Slight changes in the height will occur in reality, but they are small, as the melting flux of the ingot is $\approx 0.5 \mathrm{pct} \mathrm{h}^{-1}$ of the entire liquid zinc in the bath.

The presence of the ingot in the zinc bath is the reason for two sources: (1) $q_{T_{i}}$ which takes into account the local decrease of temperature due to latent heat of fusion and (2) $q_{I_{i}}$ which takes into account the source of aluminum, which is added to form a $\mathrm{Fe}_{2} \mathrm{Al}_{5}$ phase between the steel strip and the adhering zinc.

The average consumption (mass flux) $\dot{m}\left(\mathrm{~kg} \mathrm{~s}^{-1}\right)$ of ingots during the production cycle was recorded. The corresponding source term of the melting is the sum of the energy required for the heating up and the latent heat of fusion $H_{S}\left(\mathrm{~J} \mathrm{~kg}^{-1}\right)$ of the ingot:

$$
q_{T_{i}}=\dot{m} \frac{c_{p_{Z n}} \Delta T+H_{S}}{V},
$$

where the volume $V$ is the entire volume of the computational cells, where the source term is applied.

A similar approach is applied for the solution of the aluminum transport equation, where the source term $q_{I_{A l}}$ is defined as

$$
q_{I_{A l}}=\dot{m} \frac{y_{A l}}{V},
$$

where $y_{A l}$ is the mass fraction of aluminum in the ingot. The source term for all other species is zero.

\section{Species outlet}

The liquid zinc that is withdrawn with the steel strip contains a certain amount of aluminum and iron. In order to ensure species mass balance, a sink term similar to that from the ingot melting is defined:

$$
q_{O_{i}}=\dot{m} \frac{y_{i}}{V} .
$$

This approach assumes that the mass, melted from the ingot, equals the mass that adheres at the steel strip. The subtraction of Eq. [11] from [10] is equivalent to the approach reported in Reference 15.

\section{Surface strip reactions}

The correct modeling of the aluminum uptake and iron dissolution at the steel-strip zinc bath interface is crucial in order to obtain meaningful results. The local concentration and temperature distribution have a huge influence on the actual dissolution kinetics, as a metastable equilibrium between the iron in the steel strip and the liquid zinc alloy is established. ${ }^{[12]}$

The applied model relies on the results of a sophisticated 1D model, which relates the spatial iron dissolution and aluminum uptake to the local temperature and aluminum concentration. ${ }^{[11]}$ Once the local species distribution and the temperature are calculated, the corresponding surface reaction rates $m_{i}\left(\mathrm{~kg} \mathrm{~m}^{-2}\right)$ are interpolated into these values, and taken into account as source term:

$$
q_{S_{F e}}=2 m_{F e} \frac{w_{s} v_{s}}{V} \gamma
$$


The width $w_{s}$ and velocity $v_{s}$ of the steel strip are required to convert the area-related dissolution rate $m_{\mathrm{Fe}}$ to a volumetric source term $q_{S_{F e}}$. $V$ is again the volume of the reacting computational cells and $\gamma$ is a weighting factor, defined later in Eq. [14]. The source term for the aluminum uptake is defined analogously:

$$
q_{S_{A l}}=-2 m_{A l} \frac{w_{s} v_{s}}{V} \gamma
$$

Measurements and simulations showed that it takes approximately 0.2 second to form a continuous $\mathrm{Fe}_{2} \mathrm{Al}_{5} \mathrm{Zn}_{x}$-layer, and that during this period, $\sim 71 \mathrm{pct}$ of the aluminum in the interface alloy is consumed. After this period of 0.2 second, the further uptake of aluminum significantly slows down because the process becomes diffusion controlled. ${ }^{[12,26]}$ The weighting factor $\gamma$ is thus defined as

$$
\gamma= \begin{cases}0.71 & t \leq 0.2 \text { second } \\ 0.29 & t>0.2 \text { second }\end{cases}
$$

The 1D model presented in Reference 11 only resolves the diffusion layer in the close vicinity of the steel-strip surface. Usually, this diffusion boundary layer is not resolved in the simulations of the entire zinc bath, since the required computational effort is prohibitive. However, the aluminum uptake and the iron dissolution are related to the bulk aluminum concentration, which corresponds to the value of the computational cell adjacent to the solid steel strip. Furthermore, the implemented model assumes that an instantaneous formation of the inhibition layer takes place, discerning only two discrete conditions: Firstly, high dissolution with no inhibition layer (denoted as reaction zone with $\gamma=0.71)$; secondly, low, diffusion-controlled, dissolution (diffusion zone with $\gamma=0.29$ ). The length of the reaction zone is adapted according to the steel-strip velocity. Thus, two source terms with different $\gamma$ are set for both the iron dissolution and the aluminum uptake, as proposed in Eq. [14]. However, the sum of both $\gamma$ equals to 1 , in order to ensure mass balance. In reality, a mixed condition will prevail, where the surface is partly covered with the inhibition layer. However, the entire amount of dissolved iron is still predicted correctly.

\section{E. Thermodynamic Solubility}

In the process of the hot-dip galvanizing, a threephase system prevails in the molten zinc bath: the ingot supplies zinc and aluminum, whereas undesired iron dissolves into the bath mainly from the steel strip, and to a lesser extent from the bath hardware. Several studies have examined the $\mathrm{Zn}-\mathrm{Al}-\mathrm{Fe}$ system and thoroughly describe the solubility limit of iron. ${ }^{[8,9,27-29]}$ This paper focuses on the formation of the $\delta$ - and the $\eta$-phase, since the presence of the $\zeta$-phase is not likely in the zinc bath within an operation window between 0.11 and $0.2 \mathrm{wt}$ pet of aluminum.

The $\eta$-phase is an aluminum-iron compound with a small amount of $\mathrm{Zn}\left(\mathrm{Fe}_{2} \mathrm{Al}_{5} \mathrm{Zn}_{x}\right)$, whereas the $\delta$-phase consists mainly of zinc and iron with some aluminum $\left(\mathrm{FeZn}_{7-11} \mathrm{Al}_{x}\right) \cdot{ }^{[8,9,27-29]}$ The actual number of zinc atoms in the phase has been disputed, and it resulted in $\mathrm{FeZn}_{10} \mathrm{Al}_{x} \cdot{ }^{[8]}$ However, the thermodynamic data used in this model is based on Reference 27, where the $\delta$-phase is defined as $\mathrm{FeZn}_{7}$. This approach is also reported in Reference 15

According to Reference 27, the solubility limit in mass fraction of pure iron in zinc without aluminum can be calculated as

$$
\frac{y_{F e}^{0}}{100 \mathrm{pct}}=\exp \left(17.78-\frac{15388}{T}\right) \text {. }
$$

To determine the solubility of $\mathrm{Fe}$ in the $\mathrm{Zn}-\mathrm{Al}$ alloy, the following approach is employed ${ }^{[27]}$ :

- phase $\zeta$ :

$$
y_{F e}=y_{F e}^{0} \exp \left(14 \frac{4.1 X_{\zeta} X_{A l}+X_{\zeta} \ln X_{\zeta}+X_{A l} \ln X_{A l}}{X_{\zeta}}\right)
$$

$$
\text { with } \quad X_{\mathrm{Al}}=0.00164 y_{\mathrm{Al}} \quad \text { and } \quad X_{\zeta}=1-X_{A l} \text {, }
$$

where $X_{A l}$ is the molar fraction of aluminum in the $\zeta$-particles, and $y_{A l}$ and $y_{F e}$ are the mass fraction of aluminum and iron in the liquid alloy.

- phase $\delta$ :

$$
y_{F e}=1.22 y_{F e}^{0} \exp \left(8 \frac{3 X_{\delta} X_{A l}+X_{\delta} \ln X_{\delta}+X_{A l} \ln X_{A l}}{X_{\delta}}\right)
$$

$$
\text { with } \quad X_{\mathrm{Al}}=0.0042 y_{\mathrm{Al}} \quad \text { and } \quad X_{\delta}=1-X_{A l} \text {. }
$$

Experimentally obtained liquidus line of the $\eta$-phase is given in Reference 27 as

- phase $\eta$ :

$$
y_{F e}^{2} y_{A l}^{5}=\exp \left(28.1-\frac{33066}{T}\right) \text {. }
$$

Isothermal sections of the zinc-rich corner of $\mathrm{Zn}-\mathrm{Al}$-Fe phase diagram for temperatures $725 \mathrm{~K}$ and $735 \mathrm{~K}$ are shown in Figure 2 in order to provide an idea of temperature dependence of liquidus lines.

\section{F. Thermodynamic Evaluation of Dross Build-Up Formation}

The CFD model provides species concentrations and temperature in each computational cell. This allows a thermodynamic assessment of the local driving force for dross formation. Consider the point A corresponding to the local liquid melt composition shown in Figure 2. The distance between point $\mathrm{A}$ and point $\mathrm{B}$, corresponding to the thermodynamic solubility limit, is the 
thermodynamic driving force for the formation of dross. In this example, the iron concentration is too high so dross particles form. In order to assess the dross formation driving force, the lever rule can be applied. The farther the concentrations in the liquid alloy are from the solubility line, the higher is the driving force to precipitate dross particles and to move toward the solubility limit (shown as dashed line).

This model can be used to predict the local driving force for dross particle formation in the entire zinc bath. When the dross build-up formation on the bath hardware is assessed, it has to be noted that currently only the concentration in the vicinity of the solid-liquid interface can be determined. The actual concentration at the surface depends significantly on the local fluid flow conditions. However, it is possible to draw qualitative conclusions from the thermodynamic conditions in the vicinity of the solid-liquid interface, whether or not the driving force for dross build-up formation prevails.

\section{EXPERIMENTAL AND VALIDATION}

The zinc bath temperature depth profile was measured during operation with type $\mathrm{K} /$ class I thermocouples, with a tolerance of $\sim 1.8 \mathrm{~K}$. A measurement lance was instrumented with five thermocouples with $35 \mathrm{~cm}$ intervals in order to monitor the temperature at different depths. Temperatures were measured at five different positions within the bath as shown in Figure 1. The software DasyLab ${ }^{[30]}$ recorded the data.

Furthermore, liquid samples were taken to assess the chemical composition in the zinc bath. The sampling tube consists of a closed sampling chamber with a covering plate that is activated via a handle bar. A

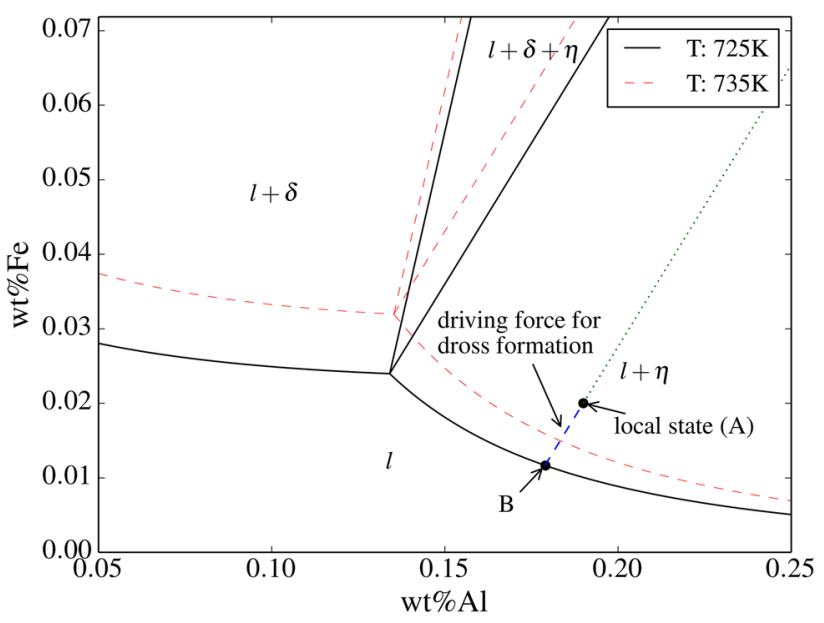

Fig. 2-Thermodynamic solubility of iron in the Zinc-rich corner of the three-phase system ( $\mathrm{Zn}-\mathrm{Al}-\mathrm{Fe})$ for two different temperatures. The significant influence of the temperature on the thermodynamic solubility can be seen, as much more iron can be dissolved in the zinc bath at higher temperatures. If a local state of the liquid zinc alloy (point A) exceeds the solubility limit, the distance to the thermodynamic solubility (point B) can be computed with the lever rule. The larger the distance, the higher the driving force for dross formation. Adapted from Ref. [27]. thermocouple, connected to the sampling chamber, measures the local temperature. It allows samples to be taken at different positions and depths. In this case, the positions 1 to 3 (in Figure 1) were chosen and samples in depths of $0.1 \mathrm{w}, 1 \mathrm{w}$ and 2.1 were taken. To determine the bath composition, inductively coupled plasma mass spectroscopy was performed on the liquid samples obtained by means of the sampling tube.

The quality of the numerical model is assessed by comparison to measurements in a real operating zinc bath. A detailed geometric model of the zinc bath, including all bath equipment (e.g., bath rolls, mounting), is shown together with the measurement positions in Figure 1. A period of nearly constant processing (i.e., steel-strip dimensions, velocities, temperatures and bath aluminum content) was chosen, to facilitate the determination of the initial conditions. The boundary conditions for the simulation correspond to the process parameters during the measurement. They are listed together with the material properties in Table I.

The simulation started with a homogeneous, bath temperature of $733 \mathrm{~K}$ and zero velocity. In order to create comparable conditions in the simulation, a full inductor cycle (heating and cooling) is computed before the temperature distribution at the measurement points is monitored. However, since the hot-dip galvanizing process is highly transient, with continuous changes in temperature and compositions, it is difficult to obtain the same initial conditions for the measurements and simulations. This makes an exact agreement difficult to obtain, as even the reproducibility of the measurement data in this transient metallurgical process is limited.

\section{A. Temperature Distribution}

The time-averaged depth profiles are plotted in Figure 3.

The surface of the liquid zinc is located at the depth of 0 and the bottom of the zinc bath is at 2.5. The measured temperature profile was very homogeneous over the depth and fluctuations were smaller than the measurement tolerance. Only at positions 1 and 2 (located near the inductors) can a warmer zinc in the top region be measured. This warmer region is also

Table I. Material Properties and Process Parameters Used for the Validation in the Simulation. The Steel Properties, the Subscript $s$ Refers to the Solid Steel Strip, Are Valid for Micro-alloyed Steels, ${ }^{[31]}$ and the Melt Properties Are Taken from the Literature ${ }^{[19]}$

\begin{tabular}{lll}
\hline Steel Strip & $\rho_{s}\left(\mathrm{~kg} \mathrm{~m}^{-3}\right)$ & 7700 \\
& $c_{p_{s}}\left(\mathrm{~J} \mathrm{~K}^{-1} \mathrm{~kg}^{-1}\right)$ & 640 \\
& $\lambda_{s}\left(\mathrm{~W} \mathrm{~m}^{-1} \mathrm{~K}^{-1}\right)$ & 35 \\
& $v_{s}\left(\mathrm{~m} \mathrm{~s}^{-1}\right)$ & 1.67 \\
& $T_{s}(\mathrm{~K})$ & 733 \\
$Z n+0.15$ pct Al at $T=733 \mathrm{~K}$ & $\rho_{l}\left(\mathrm{~kg} \mathrm{~m}^{-3}\right)$ & 6600 \\
& $c_{p_{l}}\left(\mathrm{~J} \mathrm{~K}^{-1} \mathrm{~kg}^{-1}\right)$ & 512 \\
& $\lambda_{l}\left(\mathrm{~W} \mathrm{~m}^{-1} \mathrm{~K}^{-1}\right)$ & 60 \\
$\mu\left(\mathrm{Pa} \mathrm{s}^{2}\right.$ & 0.0034 \\
& $\beta_{T}\left(\mathrm{~K}^{-1}\right)$ & $1.466 \times 10^{-4}$ \\
\hline
\end{tabular}




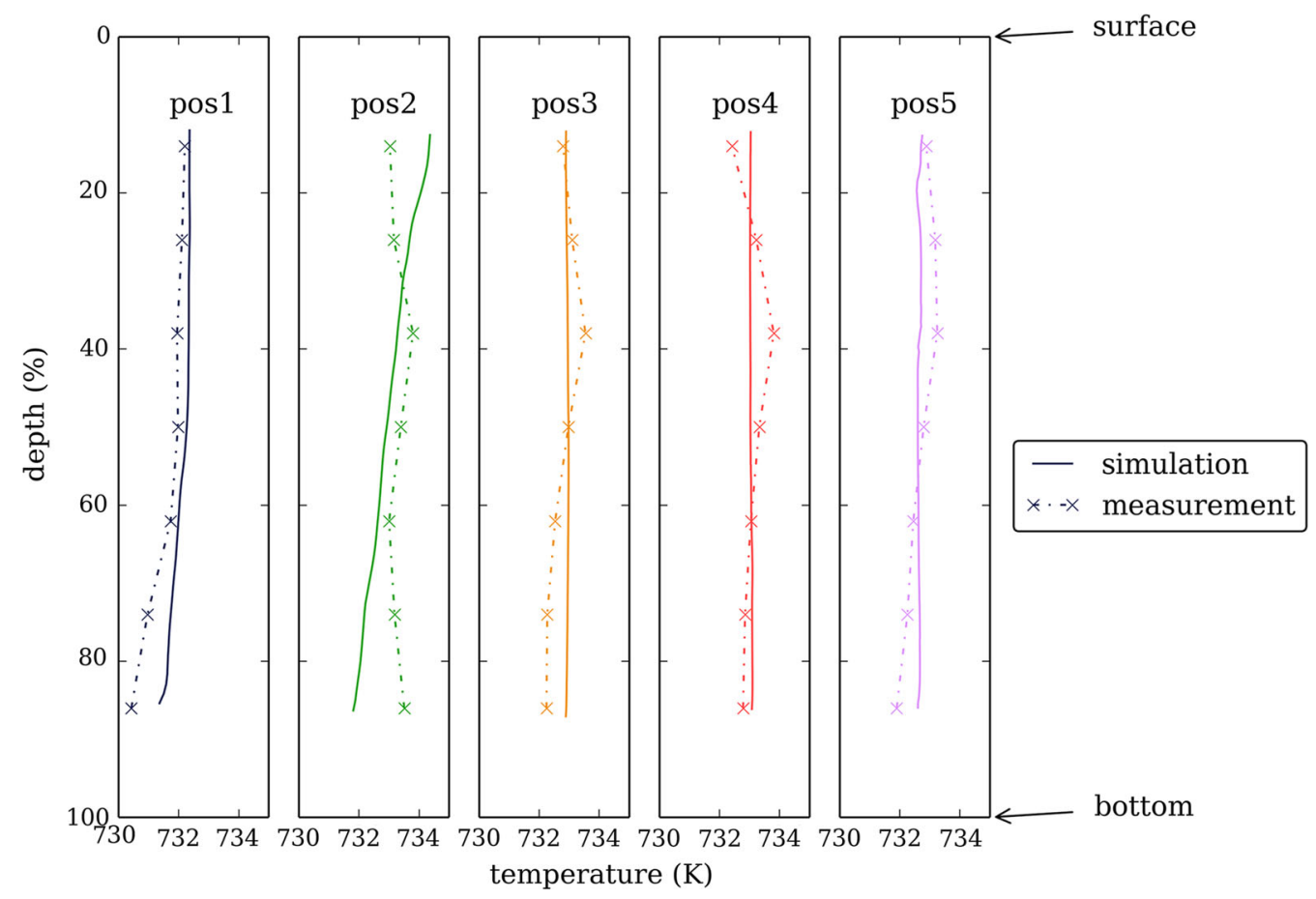

Fig. 3-Time-averaged temperature along depths at the different measurement positions. The temperature depth profile is very homogeneous in the zinc bath. Only in the inductor area (position 1 and 2) can a hotter top region be found. A good agreement between the measurement and the simulation can be seen, with a relative error of less than 0.5 pct.

reproduced by the simulation data. In general, a good agreement between the simulation and measurement can be seen.

Since the measured temperature depth profile was homogeneous, it is enough to compare the transient simulation and experiment at a depth of 50 pct. Both in the case of cooling (positions 1, 2, and 4 in Figure 4) and heating up (pos. 3 and 5 in Figure 4), the simulation predicts the temperature trend correctly. The relative error is under 0.5 pct. During the measurement at positions 3 and 5 , the inductor was switched off. At position 3 , this was at $\mathrm{t}=240$ second. The measured and simulated temperature still rises at this position for another 20 second, but afterward the simulated zinc bath starts to cool, whereas in the measurement the temperature increases slightly. It can be seen that the real zinc bath reacts more slowly to the change of the heat source compared to the simulation. However, it has to be mentioned that it is very difficult to obtain the same starting conditions for the simulation, with regard to velocity and temperature distribution compared to the real system.

\section{B. Species Distribution}

In conjunction with the monitored temperatures, the computed species concentrations at the measurement positions 1, 2, and 3 were recorded and are depicted in Figure 5. The measured concentration profile in the zinc bath is very homogeneous, which is in good agreement with simulations.

\section{RESULTS AND DISCUSSION}

This section illustrates the capability of the proposed model. It is subdivided into two parts: Firstly, the results of the spatially resolved iron dissolution and aluminum uptake at the steel-strip interface are presented, and secondly, the thermodynamic assessment of the driving force for dross formation in the bath and the dross build-up formation on the bath hardware are shown. In order to assess the impact of the models, a reference condition with a steel-strip immersing temperature of $733 \mathrm{~K}$, turned-on inductors, and constant ingot addition is chosen.

\section{A. Spatially Resolved Steel-Strip Surface Reaction}

The local effects of the temperature and aluminum concentration on the steel-strip surface reactions are evaluated. When the immersing steel strip has a different temperature than the zinc bath, two effects can be observed. Firstly, the surface temperature of the steel strip adapts to the surrounding liquid zinc temperature quickly, as seen in Figure 6 for a high steel-strip velocity (solid blue line).

The steel strip enters at 0 and reaches the bottom roll at 100 pct, where the steel strip has mostly adapted to the bath temperature. The adaption of the steel-strip temperature to the zinc bath is the result of a high heat flux in the immersing region, and makes a coupled heat transfer modeling very important, as also the temperature-dependent steel-strip surface reactions will take 
place in the first few seconds of the contact. Secondly, local effects across the strip width can be seen. The edges of a steel strip adapt more quickly to the surrounding zinc bath temperature resulting in a temperature deviation between the center line and the edges perpendicular to the moving direction (dashed line in Figure 6), resulting in cooler steel-strip edges in this case.

In addition, the iron dissolution rate is plotted in Figure 6. The iron dissolution at the cooler edges is slightly smaller than in the middle of the strip, which might result in different $\mathrm{Fe}_{2} \mathrm{Al}_{5}$ layer thicknesses on the coated steel strip. The deviation between the center line and the edges is shown as a dashed green line in

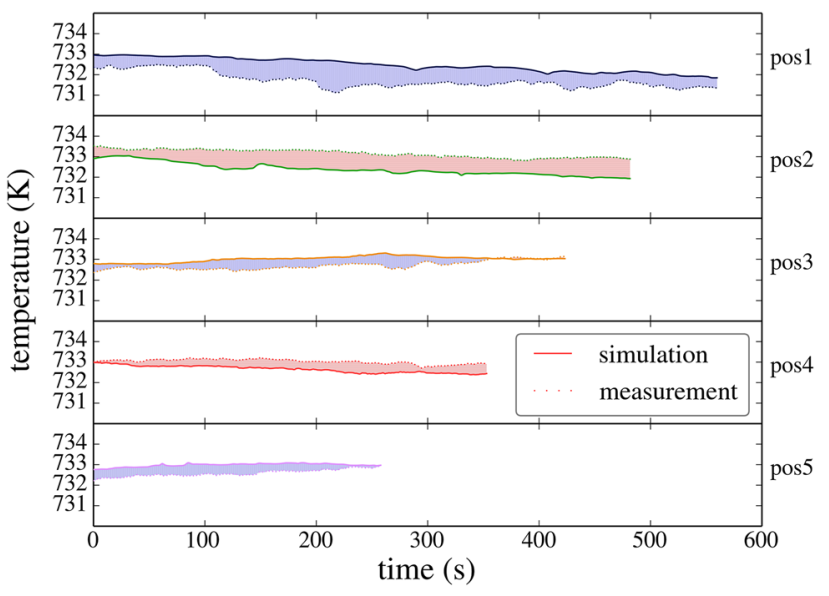

Fig. 4-Temperature at different measurement positions over time at a depth of 50 pct. The duration of the individual measurements varies and they were carried out consecutively. The continuous line represents the simulation data, while the dashed line refers to the measurement. A blue shading corresponds to an overestimation of the temperature, a red shading to an underestimation. A good agreement of the temperature evolution can be seen, with a relative error less than 0.5 pct (Color figure online).
Figure 6. The iron dissolution rate is affected by how the steel-strip temperature adapts to the bath temperature. After the inhibition layer is formed in the reaction zone, the iron dissolution will drop significantly, as the process becomes diffusion controlled.

The local influence of the bath and operating conditions (for example inductor operation) on the aluminum uptake is depicted in Figure 7, with a steel-strip immersing temperature of $T_{s}=733 \mathrm{~K}$. The overall temperature in the bath is higher with working inductors, which pump and heat up the liquid zinc. The higher bath temperature increases the aluminum uptake, as seen in Figures 7(a) and (c). In addition, differences in aluminum uptake can be observed between the top steel-strip side, in contact with the bottom roll, and the bottom steel-strip side. When the inductor is turned off, the aluminum uptake is lower because of the lower bath temperature (see Figures 7(b) and (d)). Although clearly distinguishable, these spatial differences within the reaction zone are small compared to the differences of the iron dissolution in the reaction zone and the diffusion zone.

Given these results, it follows that the spatially resolved temperature and species boundary condition on the steel-strip interface (subdivision into reaction and diffusion zone) have a significant influence on the simulation results for two reasons. Firstly, the correct computation of the iron distribution within the zinc bath is mainly dependent on its source, which is the steel strip. Secondly, the temperature has a significant effect on the thermodynamics and only slight changes can shift the solubility. ${ }^{[1]}$

\section{B. Thermodynamic Evaluation of Dross Formation in the Zinc Bath}

Once the local temperature and species concentrations are computed with the CFD model, the thermodynamic evaluation of dross precipitation in the zinc bath and dross build-up formation on the bath hardware can be

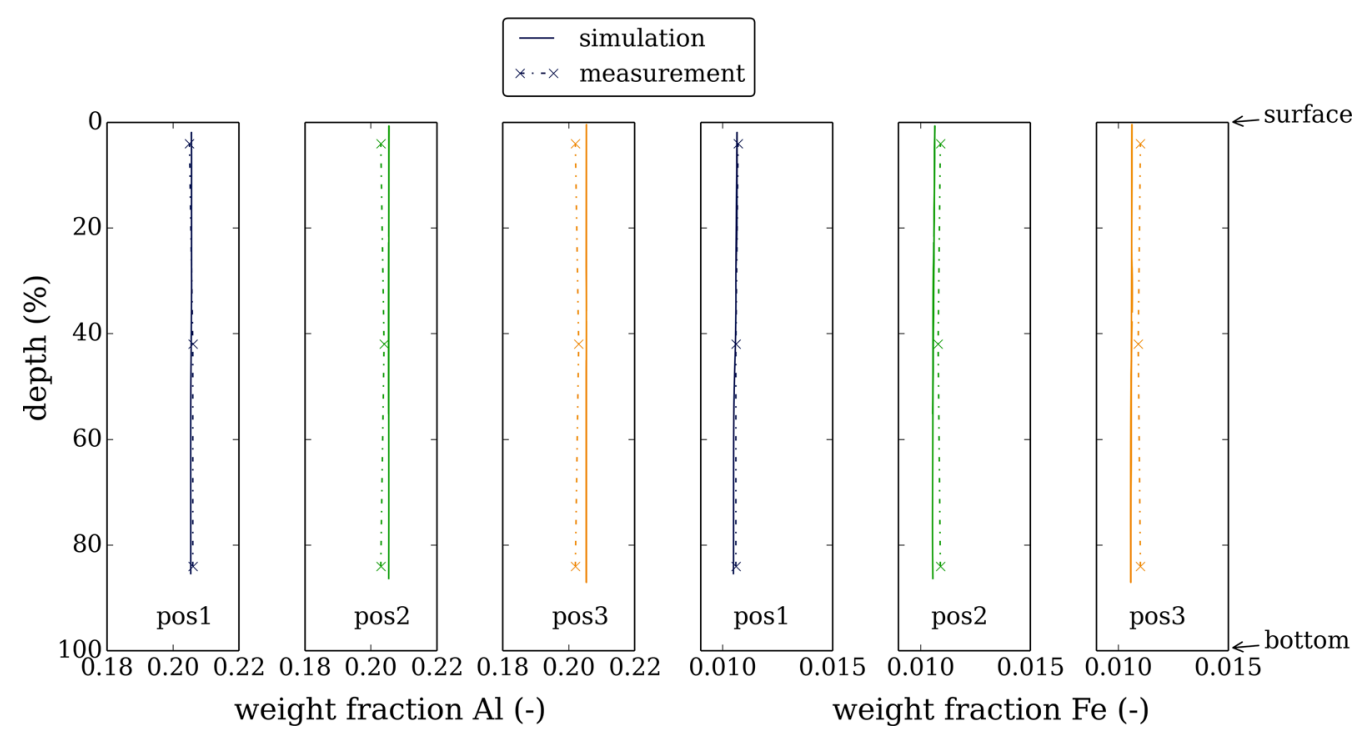

Fig. 5- Species concentration in liquid zinc alloy along depths at different measurement positions. The species depth profile is very homogeneous in the zinc bath. The simulation results show a slight shift in regions far away from the ingot, compared to the measured values, but the profiles show a good agreement. 


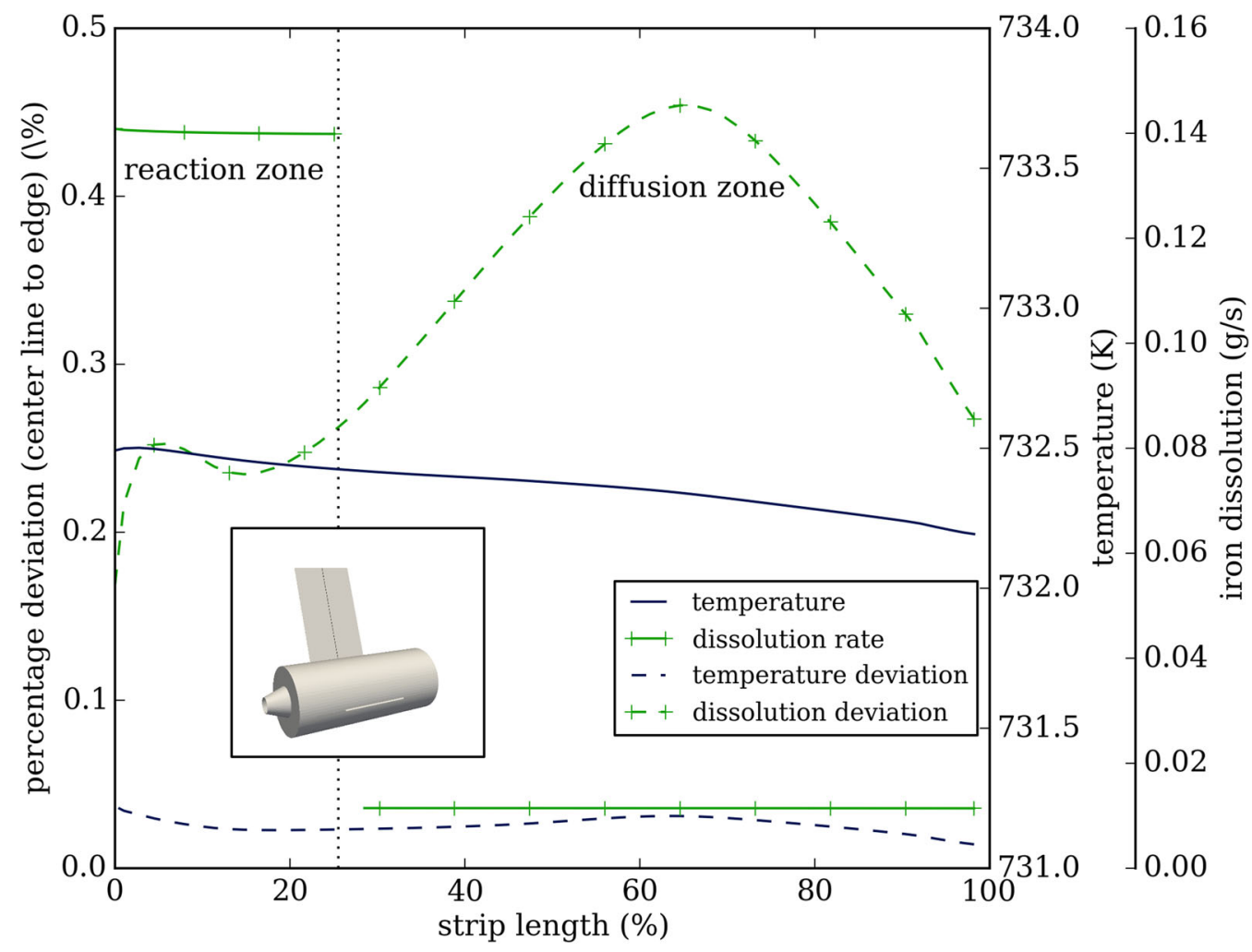

Fig. 6-The surface temperature and iron dissolution (solid lines) of the immersing steel-strip section along the moving direction at the center line. The dashed lines represent the percentage deviation between the edge and the center line. The strip enters at 0 , with a velocity of $2.5 \mathrm{~ms}^{-1}$, and reaches the bottom roll at 100 pct. After the inhibition layer is formed, the iron dissolution drops to lower values in the diffusion zone (solid green line). The temperature adapts to the surrounding bath temperature (solid blue line). A slight percentage deviation between the temperature at the center and the edges can be seen. The temperature adapts more quickly at the edges, which leads to cooler edges and a lower iron dissolution at the edges (Color figure online).

assessed. A global picture of the zinc bath is shown in Figure 8. The steel-strip entry temperature is $T_{s}=$ $733 \mathrm{~K}$ and the mean weight fraction of aluminum is 0.2. The cross section in Figure 8 is subdivided into following areas:

1. The green area is where a fast dissolution of dross particles can be assumed, as the local thermodynamic state in the liquid alloy is far away from the solubility. In this case, a warmer zinc alloy from the inductor enables a dissolution of particles.

2. The yellow area refers to nearly saturated liquid alloy, where only a slight dissolution of dross particles can be anticipated.

3. The orange area is again near the solubility limit, with a low positive driving force for the precipitation of dross particles.

4. Red areas correspond to a high driving force for the formation of dross particles. The formation will occur either in regions with high aluminum content (e.g., ingot addition) or in cooler areas.

This thermodynamic assessment enables a detailed study of the local dross formation tendency in the bath for different process conditions.

\section{Thermodynamic Evaluation of Dross Build-Up Formation}

The thermodynamic evaluation model is applied to analyze the driving force of dross build-up formation on the bath bottom roll. A reference condition with a mean bath temperature of $\approx 733 \mathrm{~K}$ and a constant ingot addition with an aluminum weight fraction of 0.55 is set as boundary condition. Figure 9 shows a summary of the species concentrations, the temperature, and the driving force for precipitation at the bottom roll surface. In these plots, the surface of the bottom roll is projected to a plane surface and a contour plot of the local quantities is depicted. The steel strip enters at the right-hand side and leaves at the left-hand side. The white rectangle on the right-hand side of the contour plot is the contact zone between the roll and the steel strip, where no fluid flow is calculated.

The first interesting result is that the concentrations in the vicinity of the roll surface are very homogeneous for aluminum and iron (see first row in Figure 9). This is also in agreement with the measurement results, which show a homogeneous species concentration in the zinc bath. 
inductor turned on

steel strip

top side

steel strip

bottom

side (a)

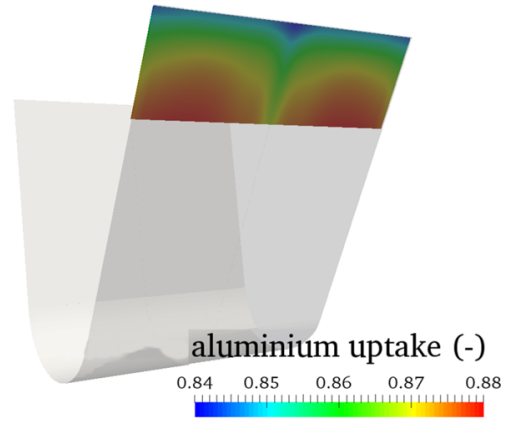

(c)

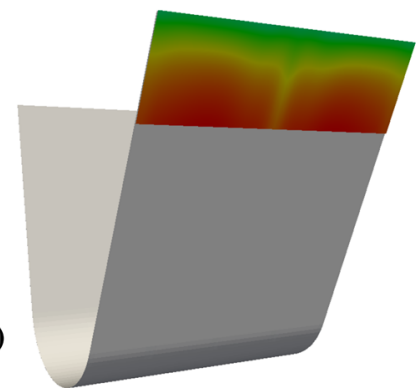

(b)

\section{inductor turned off}

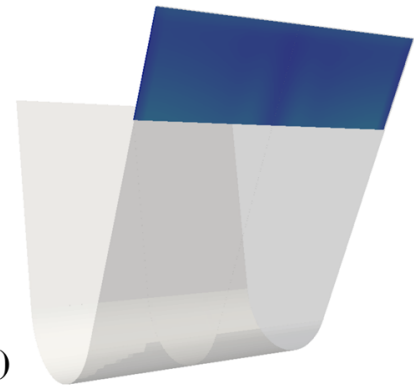

(d)

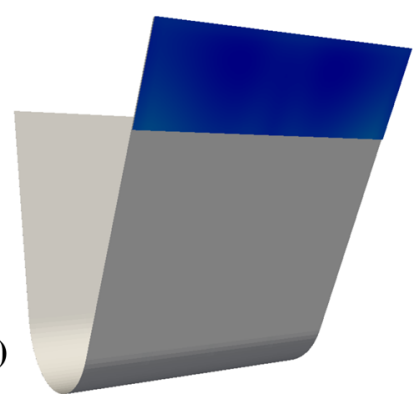

Fig. 7-Locally resolved aluminum uptake in the immersing section of the steel strip denoted as reaction zone. The steel-strip immersing temperature is $T_{s}=733 \mathrm{~K}$. The left-hand column shows the bath condition at turned-on inductors. The resulting higher bath temperature yields a higher aluminum uptake. Interestingly, the aluminum uptake differs between the top strip side, in contact with the bottom roll $(a)$ and $(b)$, and the bottom strip side $(c)$ and $(d)$, because of slightly different temperature distributions. The right-hand side depicts the same situation with turned-off inductors. The aluminum uptake is lower and slight edges effects can be seen.

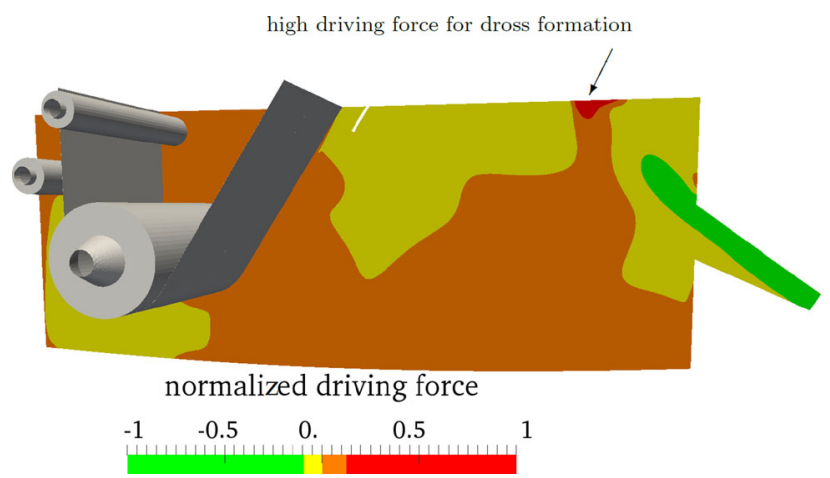

Fig. 8-Normalized driving force for precipitation of $\mathrm{Fe}_{2} \mathrm{Al}_{5}$ in the zinc bath, deduced from the distance to the thermodynamic solubility. Green areas refer to a high dissolution rate, due to a warmer zinc from the inductors. In general, the zinc bath is near the thermodynamic solubility with slightly warmer regions (yellow) with a small driving force for dross dissolution. The larger volume of the zinc bath shows a slight tendency for dross formation (orange). The strip entry temperature is $T_{s}=733 \mathrm{~K}$ and the inductors are turned on (Color figure online).

Secondly, slight temperature variations can be seen at the bottom roll (see lower left picture in Figure 9). These variations are influenced by various operating conditions, such as the heating of the zinc bath, the steel-strip velocity and temperature, ingot melting.

Thirdly, these small temperature variations are sufficient to change the local thermodynamic condition as summarized in the lower right picture in Figure 9. The driving force for precipitation is normalized between -1 and 1 , where -1 corresponds to high dissolution and 1 corresponds to high precipitation. Consequently, a value of 0 corresponds to solubility equilibrium. The conditions in the reference condition show a slight growth of dross build-up on the bottom roll. This corresponds with the observation that during standard operating conditions dross build-up occurs at the roll surfaces.

The simulation results suggest that a microclimate can prevail around the bottom roll. The effect on the thermodynamic driving force for the precipitation of dross build-up will change significantly depending on the current process boundary conditions, e.g., inductor cycle, ingot addition, steel-strip conditions.

\section{CONCLUSION}

In operating continuous galvanizing lines, a major goal is to control and reduce dross build-up. Here a physically sound CFD model to predict dross particle formation in the entire zinc bath and dross build-up on the bath hardware has been presented.

The flow, temperature, and species concentrations in the zinc bath are computed. The deviation to the thermodynamic equilibrium is taken as a measure for the driving force to precipitate or dissolve dross build-up. The correct modeling of the steel-strip interface influences the temperature and spatially resolved iron dissolution and aluminum uptake. These parameters have a significant influence on the thermodynamic conditions in the vicinity of the bath hardware. 


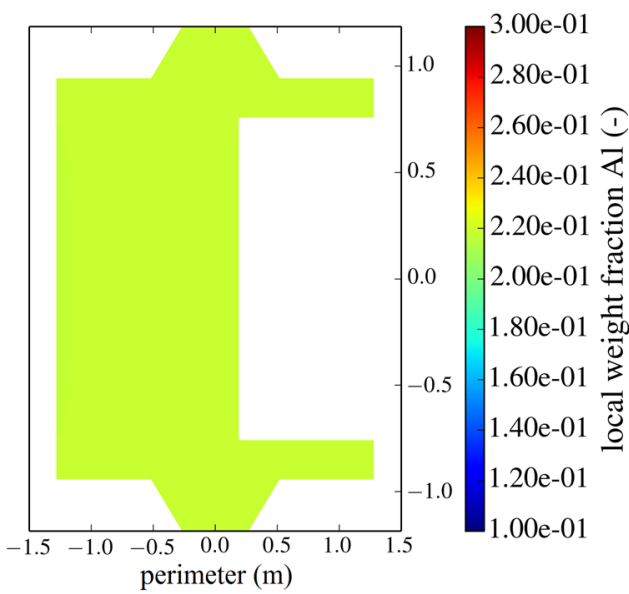

(a)

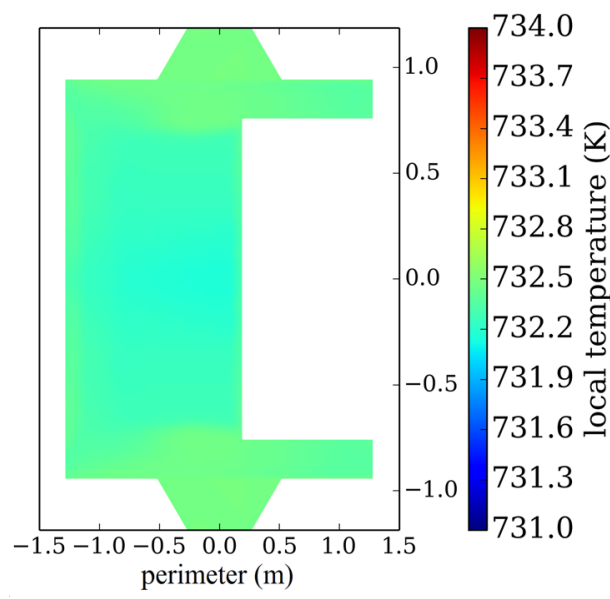

(c)

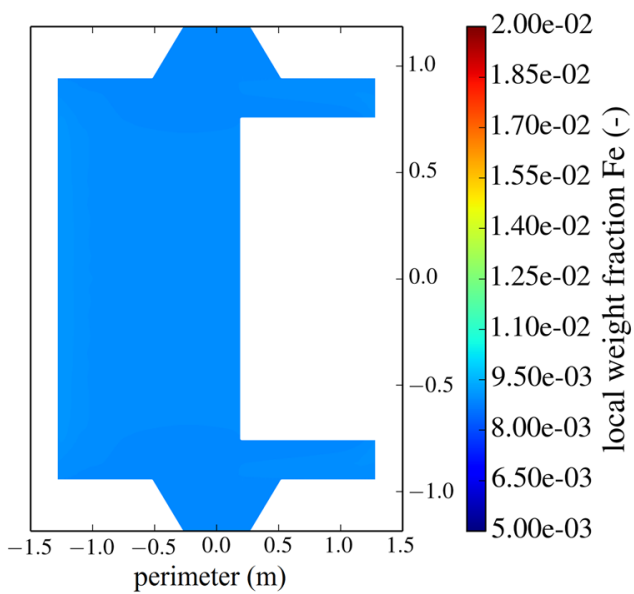

(b)

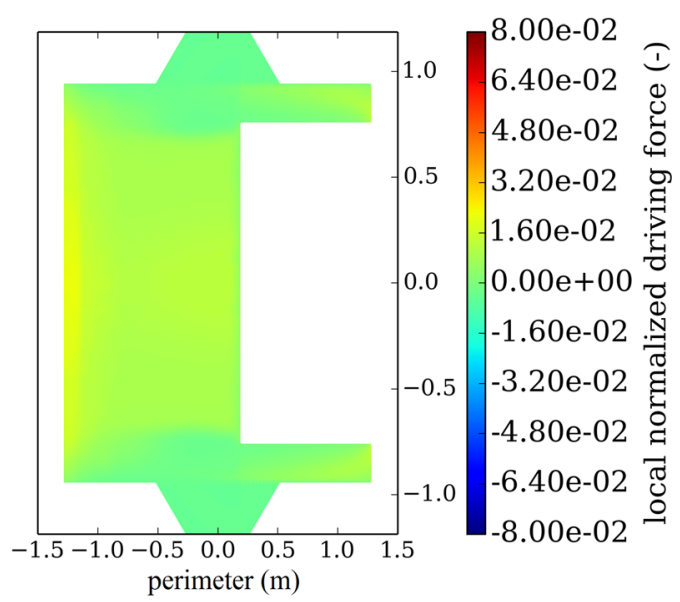

(d)

Fig. 9-The contour plot depicts the local concentrations, temperature, and driving force for precipitation at the roll surface for a steel-strip immersing temperature of $T_{s}=733 \mathrm{~K}$. The white rectangle represents the contact area between the steel strip and the roll surface, where no concentrations are computed. The steel strip enters at the right-hand side and leaves at the left-hand side. Different local driving forces for precipitation which is normalized between -1 (dissolution of dross build-up) and 1 (formation of dross build-up) can be distinguished.

The computational model has been validated by temperature and species distribution measurements in an operating zinc bath. A good agreement between simulation and measurement has been seen.

In order to show the capability of the computational model with the evaluation of the thermodynamic driving force, the local conditions in the entire zinc bath and in the vicinity of the bath roll are evaluated. A direct link between global process conditions, e.g., inductor cycle, ingot addition, and steel-strip conditions, and the tendency of dross build-up formation can be drawn.

The formulation of the spatially resolved boundary conditions of the CFD model ensures an accurate computation of the species distribution. The novel thermodynamic evaluation approach for the vicinity of the bath hardware will enable further study of how process parameters influence local effects of dross build-up.

\section{ACKNOWLEDGMENTS}

The authors gratefully acknowledge the financial support under the scope of the COMET program within the K2 Center 'Integrated Computational Material, Process and Product Engineering (IC-MPPE)' (Project No 859480). This program is supported by the Austrian Federal Ministries for Transport, Innovation and Technology (BMVIT) and for Digital and Economic Affairs (BMDW), represented by the Austrian research funding association (FFG), 
and the federal states of Styria, Upper Austria and Tyrol.

\section{OPEN ACCESS}

This article is distributed under the terms of the Creative Commons Attribution 4.0 International License (http://creativecommons.org/licenses/by/4.0/), which permits unrestricted use, distribution, and reproduction in any medium, provided you give appropriate credit to the original author(s) and the source, provide a link to the Creative Commons license, and indicate if changes were made.

\section{REFERENCES}

1. International Zinc Assosiation. Zinc/zinc-alloy/aluminum continuous sheet coating lines - North America. http://www.galvinfo.co $\mathrm{m} /$ Documents/North\%20American $\% 20 \mathrm{HD} \% 20 \& \% 20 \mathrm{EG} \% 20 \mathrm{Li}$ nes-GalvInfo-2016-02-02\%20SI.pdf. Accessed 1 July 2017.

2. G.W. Dallin. Galvanizing-2014 continuous hot-dip galvanizing - process and prodcuts. http://www.galvinfo.com/Documents/ Galvanizing\%202014.pdf. Accessed 15 July 2017.

3. C.A. Triebl, C. Spijker, H. Raupenstrauch, A. Jarosik, G. Angeli: AIChE 2014 Annual Meeting, 2014.

4. C.A. Triebl, C. Spijker, H. Raupenstrauch, A. Jarosik, and G. Angeli: INFUB 2015-10th European Conference on Industrial Furnaces and Boilers, 2015.

5. C. Pfeiler, W. Eß1, G. Reiss, C.K. Riener, G. Angeli, and A. Kharicha: Steel Res. Int., 2017, vol. 88, art. no. 1600507.

6. W. Eß1, C. Pfeiler, G. Reiss, W. Ecker, C.K. Riener, and G. Angeli: Steel Res. Int., 2018, vol. 89, art. no. 1700362.

7. J.P. Mogeritsch, A. Ludwig, B. Boettger, G. Angeli, C.K. Riener, and R. Ebner: Coupled Problems 2017, ed. by M. Papadrakakis, E. Onate, B. Schrefler, 2017.

8. J. McDermid, M. Kaye, and W. Thompson: Metall. Mater. Trans. $B, 2007$, vol. 38B, pp. 215-30.
9. J. Nakano, D.V. Malakhov, S. Yamaguchi, and G.R. Purdy: Calphad, 2007, vol. 31, pp. 125-40.

10. N.Y. Tang: Metall. Mater. Trans. A, 1995, vol. 26A, p. 1699.

11. Y.H. Liu and N.Y. Tang: in Galvatech 2004, 2004.

12. M.L. Giorgi, J.B. Guillot, and R. Nicolle: J. Mater. Sci., 2005, vol. 40, pp. 2263-68.

13. G. Mandal, R. Balasubramaniam, and S. Mehrotra: Metall. Mater. Trans. A, 2009, vol. 40A, pp. 637-45.

14. F. Ajersch, F. Ilinca, and J.F. Hetu: Metall. Mater. Trans. B, 2004, vol. $35 \mathrm{~B}$, pp. $171-78$.

15. F. Ilinca, F. Ajersch, C. Baril, and F.E. Goodwin: Int. J. Numer. Method Fluids, 2007, vol. 53, pp. 1629-46.

16. F. Ajersch, F. Ilinca, F. Goodwin: Association for Iron and Steel Technology 2013, vol. 2, pp. 1145-1152, 2013.

17. D.E. Hryb and M.B. Goldschmit: ENIEF 2006, 2006.

18. K. Yu, F. Ilinca and F. Goodwin: AISTech-Iron and Steel Technology Conference Proceedings 2016, pp. 2043-2053, 2016.

19. M. Mataln, C. Pfeiler, J. Strutzenberger, and G. Angeli: Galvatech 2015-10th International Conference on Zinc and Zinc Alloy Coated Steel Sheet, 2015.

20. H.K. Versteeg and W. Malalasekera: An Introduction to Computational Fluid Dynamics, Longman Scientific \& Technical, Harlow, 1995.

21. J.H. Ferziger and M. Peric: Computational Methods for Fluid Dynamics, Springer, New York, 2002.

22. R. Schwarze: CFD-Modellierung. Grundlagen und Anwendungen bei Strmungsprozessen, Springer, New York, 2013

23. S.B. Pope: Turbulent Flows, Cambrige University Press, Cambrige, 2000.

24. ANSYS FLUENT Theory Guide, 2018.

25. E. Specht: Waerme-und Stoffuebertragung in der Thermoprozesstechnik, Vulkan Verlag, Essen, 2014.

26. P. Toussaint, L. Segers, R. Winand, and M. Dubois: ISIJ Int., 1998, vol. 38, p. 985.

27. N.Y. Tang: J. Power Electron., 2000, vol. 21, pp. 70-77.

28. N.Y. Tang: Mater. Sci. Technol., 1995, vol. 11, pp. 870-73.

29. M.L. Giorgi, J.B. Guillot, and R. Nicolle: Calphad, 2001, vol. 25, pp. 461-74.

30. Measurement Computing Corporation. Dasylab ${ }^{\circledR}$. https://www. mccdaq.com/products/DASYLab.aspx. Accessed 9 Sept 2017.

31. F. Richter, Stahleisen-Sonderberichte, Heft 10, 1983. 